\title{
Comparison of Infrared Thermography with Ground-Penetrating Radar for the Non- Destructive Evaluation of Historic Masonry Bridges
}

\author{
by S. Lagüela*, M. Solla*, J. Armesto* and H.González-Jorge*
}

*Photogrammetry and Remote Sensing Research Group, Mining Engineering Technical School, University of Vigo, Campus Lagoas - Marcosende, Rúa Maxwell s/n - 36310 Vigo, Spain, <susiminas, merchisolla, julia, higiniog@uvigo.es>

\section{Abstract}

Water content in masonry bridges is a key factor on their conservation, as it affects their structure. But its detection requires the use of non-destructive techniques that do not perturb the actual state of the bridge. Infrared thermography and ground-penetrating radar have proved to be appropriate techniques for the surveying of masonry elements and for detection of moisture areas in different materials, used both independently and combined. These techniques are applied together to the detection and analysis of moisture areas in a historic masonry bridge in order to provide information for subsequent conservation actions.

\section{Introduction}

In the last decades, there has been a continuous increase of social concerns for the conservation, protection and enhancement of historical monuments. Consequently, due to the historical character of these structures, the use of non-destructive testing (NDT) is recommended for their evaluation, as it does not alter the condition of the bridge. There are many non-destructive techniques that have been used in the study of cultural heritage (such as sonic/ultrasonic, electromagnetic and electrical methods, as well as infrared thermography), but, although all of them are appropriate for these studies, none of them is able to stand as a unique, decisive technique. Thereby, the use of several NDT techniques in the same study is very common, as can be seen in [1, 2]. In these studies, each NDT method provides different information regarding the physical properties of the masonry structure, but the combination of results enables to reach the same conclusions.

The detection of moisture areas is fundamental for bridge conservation, especially if the bridge suffers traffic loads, mainly because the presence of water in the fill reduces the load capacity of the structure. What is more, if water content is sufficiently high, it can cause severe damage, such as material degradation, dissolution of compounds, salt migration and crystallization, or volumetric changes that lead to the appearance of faults in the structure, such as swelling or cracking [3]. Infrared thermography is a non-destructive technique with which moisture can be detected, especially in porous materials, as it was proved in several studies such as [4,5], given the cooling effect of evaporation on the surface. On the other hand, ground-penetrating radar has also been used in the detection of water inside structures due to the attenuation that water provokes in the signal [6]. Thus, the combination of these techniques can be applied to the characterization and monitoring of historical structures, as shown in some published studies, such as [7, 8].

In the case presented in this paper, a historic masonry bridge was inspected by combining the techniques of infrared thermography and ground-penetrating radar (GPR), in order to confirm the presence of possible moisture areas detected by the GPR in previous inspections, presented in [9], due to the importance of water content on the durability and stability of the bridge.

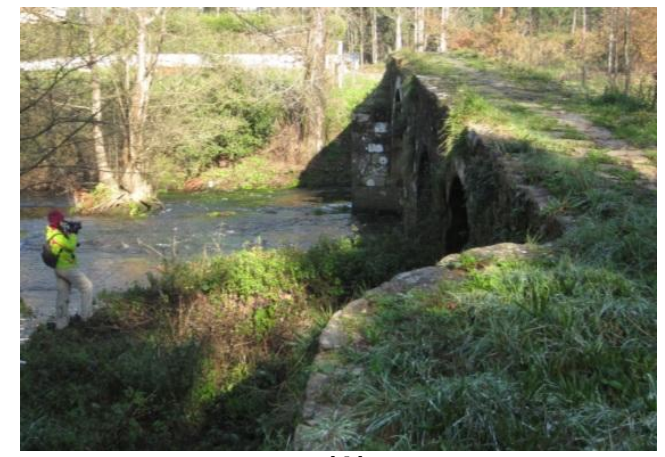

(A)

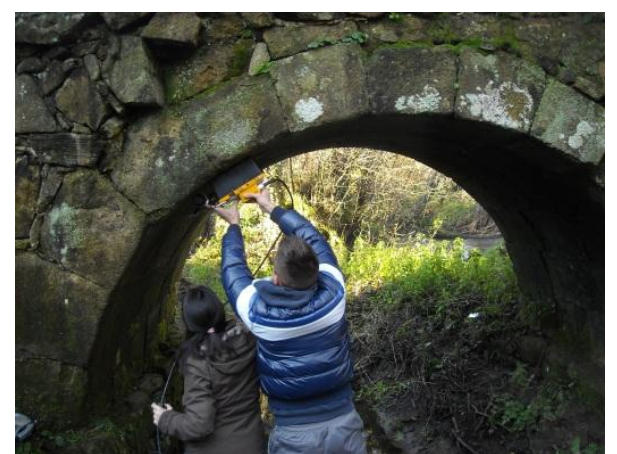

(B)

Fig.1. Thermographic survey on the first arch upstream $(A)$ and GPR survey over the vault of the same arch (B) 
The thermographic survey includes the whole bridge, and its aims are to confirm the presence of higher water content in the arch identified by the previous GPR study and to contribute to the detection of new moisture areas. However, the small field of view of current thermographic cameras makes the inspection of the bridge confusing given that each thermographic image represents a very small part of the bridge. Consequently, photogrammetry was used in order to generate a three-dimensional model of the bridge through the computation of the geometry from visible images acquired from different angles, as in [10]. The 3D model was textured with the thermographies acquired resulting in a thermographic 3D model of the whole bridge, and making possible the inspection of the entire bridge by using an only image instead of working with several images simultaneously. Further information about photogrammetry and different photogrammetric techniques can be found in [11].

A deeper thermographic study was performed for the arch identified as more delicate due to its water content in the previous GPR survey. For this arch, the thermographic survey and subsequent 3D model included the vault, since the vault was the part were water seemed to accumulate, regarding the results of the previous GPR survey. The thermographic 3D model is used to create a more realistic synthetic model for finite-difference time-domain (FDTD) modelling, which is a numerical modelling technique used as an interpretational tool to assist in the interpretation of the results $[12,13]$, since the comparison of field and synthetic GPR data results in subtle interpretational information that can help in the more thoroughly understanding of the radar-wave propagation phenomena.

This paper is organised as follows: Section 2 explains the working procedure for the thermographic and the GPR surveying of the bridge; Section 3 includes the different data processing developed for each type of data acquired with the different techniques; Section 4 compiles the results obtained both by the thermographic survey and the ground penetrating radar analysis; and Section 5 shows the conclusions reached after the study of the bridge by combining the two techniques.

\section{Survey methodology}

The thermographic and GPR surveys were developed in the Lubiáns Bridge, located in the municipality of Coristanco, in Galicia (Northwest of Spain). This bridge goes over the Anllóns River, and has been classified as "of historical interest" because of its Roman origins and the later reconstruction it was subjected to in the Medieval Age, when the round vaults were built. The bridge is constituted by 4 asymmetrical round arches, with a cutwater in their central part. The material used is granite, rock that has been extensively exploited through history in the region given its local nature. The deck is formed by granite flags and presents no side protection. A view of the bridge is shown in figure 2 , where the four arches are highlighted by black circles, and the arch subject of deeper study is marked with a black arrow. The dimensions of the bridge are $40.5 \mathrm{~m}$ long, $5.40 \mathrm{~m}$ high and $2.60 \mathrm{~m}$ wide, being the narrowest bridge in the region.

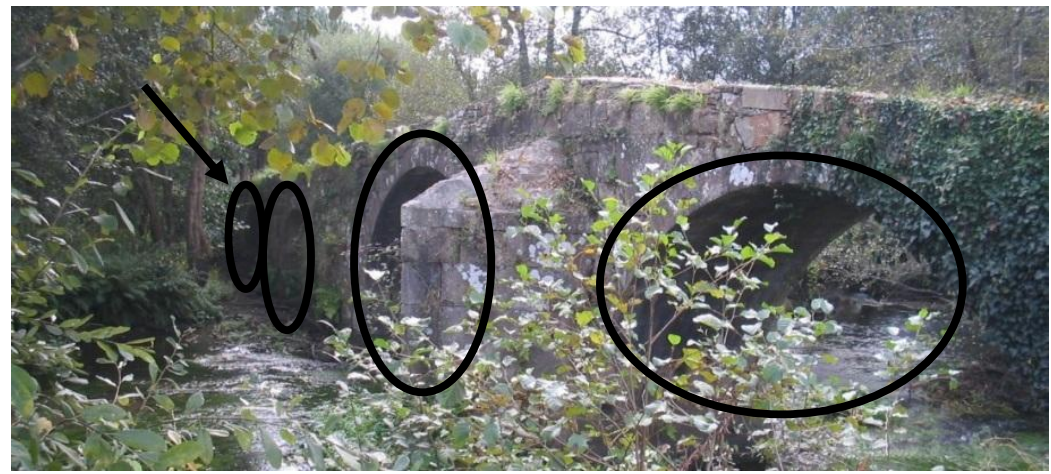

Fig.2. Side view of the Lubiáns Bridge, with its four arches highlighted by black circles. The arrow points the arch subject of deeper study due to a previous detection of moisture in it.

\subsection{Infrared thermography}

The thermographic survey was developed from a passive approach; therefore no artificial heating was applied to the bridge surface. However, the passive solar radiation was used to increase the evaporation rate of the water inside the structure and consequently maximize the temperature difference between damp and dry areas: as the surface evaporation has a cooling effect, damp areas are colder than dry ones thanks to the evaporation process stimulated by the sun [3].

The thermographic study was performed using the thermographic camera NEC TH9260, which presents a field of view of $21.7^{\circ}$ horizontally and $16.4^{\circ}$ vertically, and an Uncooled Focal Plane Array, UFPA, size $640 \times 480$. Technical characteristics of the thermographic camera used can be consulted in table 1.

The average working distance between the camera and the bridge was $5 \mathrm{~m}$, as shown in figure $1 \mathrm{~A}$, and environmental conditions were $10^{\circ} \mathrm{C}$ and $40 \%$ relative humidity. Emissivity corrections were also considered, by applying to the radiation captured by the camera an emissivity value of 0.80 . This value is obtained through the performance of an emissivity test in situ following the standard [14]. 
Table 1. Technical characteristics of the thermographic camera NEC TH9260

\begin{tabular}{|l|l|}
\hline Sensor & $640 \times 480$ UFPA \\
\hline Measurement range & $-40 @ 500^{\circ} \mathrm{C}$ \\
\hline Resolution & $0.06^{\circ} \mathrm{C}$ at $30^{\circ} \mathrm{C}(30 \mathrm{~Hz})$ \\
\hline I.F.O.V. & $0.6 \mathrm{mrad}$ \\
\hline Field of View & $21.7^{\circ}(\mathrm{H}) \times 16.4^{\circ}(\mathrm{V})$ \\
\hline Frequency & $30 \mathrm{fps}$ \\
\hline
\end{tabular}

The thermographic survey included the walls of the bridge, both for the upstream and downstream side, and also the inner part of the vault of the arch under deeper study. An example of the thermographies acquired is shown in figure 3.

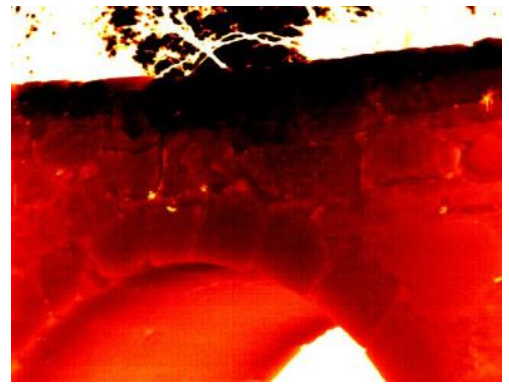

(A)

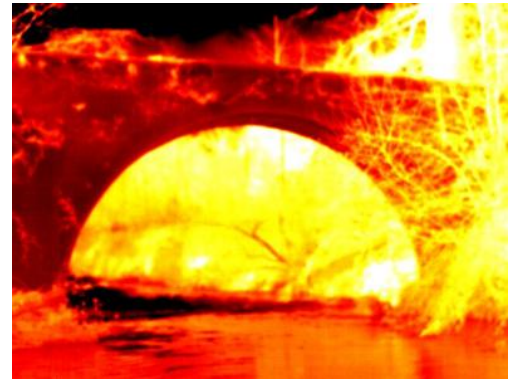

(B)

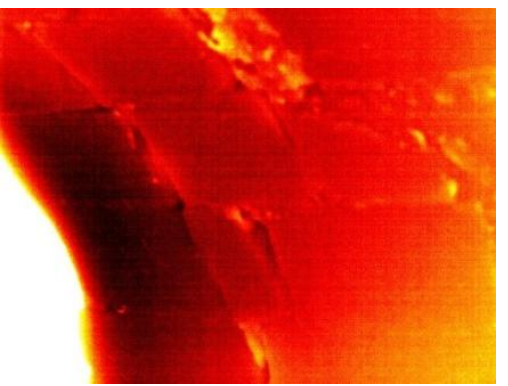

(C)

Fig.3. Example of thermographies acquired from the walls of the bridge downstream $(A)$ and upstream (B), and of the inner part of the vault of the first arch upstream $(C)$. The colour palette applied goes from $6^{\circ} \mathrm{C}$ (dark red) to $12^{\circ} \mathrm{C}$ (white).

\subsection{Ground-penetrating Radar}

A GPR survey was carried out to detect moisture areas through the analysis of the effect that moisture has on the propagation of the electromagnetic signal through masonry. Two datasets were conducted for a greater understanding of the radar-wave propagation through masonry. The first survey was performed over the pathway of the bridge and the second data acquisition was directly developed by passing the GPR antenna around the internal surface of the vault, as can be seen in figure $1 \mathrm{~B}$, in order to avoid the influence of probable moisture in masonry under wet conditions and clearly identify the ring stone thickness, which is an internal element crucial for the stability of the arch and that, consequently, affects the integrity of the bridge.

The equipment used was a RAMAC/GPR CU-II system from MALA Geoscience. The $1 \mathrm{GHz}$ antenna was chosen due to its appropriate compromise between penetration and resolution. It provides a vertical resolution of $3.5 \mathrm{~cm}$ considering an average radar-wave velocity of $14.0 \mathrm{~cm} / \mathrm{ns}$, as reported in the literature for dry granitic masonry [15]. The horizontal resolution, which is estimated assuming a distance of $1.5 \mathrm{~m}$ between the antenna and the reflector surface, results in $92.5 \mathrm{~cm}$. Both profiles, the one performed over the pathway and the other carried out over the vault, were gathered in the longitudinal direction of the bridge structure as close as possible to the outer face of the bridge. The profiles were carried out using $2 \mathrm{~cm}$ trace-intervals with a $45 \mathrm{~ns}$ total time window and 512 samples per trace. What is more, an odometer wheel was attached to back of the antenna in order to measure the length of the profile.

\section{Data processing}

Each set of thermographic and radar data acquired was processed independently in order to facilitate data interpretation and the detection of defects.

\subsection{Infrared thermography}

The first step is the analysis of the thermographies acquired in order to choose a temperature interval and a colour palette adequate for the detection of defects, especially damp areas. In this case, the chosen interval goes from 6 to $12^{\circ} \mathrm{C}$, colours going from dark red for the lowest temperatures, to red, light red, orange, yellow and white for the highest temperatures. This interval goes in coherence with the ambient conditions. Once pre-processed, images are subjected to the following processes. 


\subsubsection{Thermographic $3 D$ modelling}

Given the small field of view of the thermographic camera used for this study, the 3D model reconstruction of the bridge was accomplished by means of terrestrial photogrammetry, as performed in [16]. Consequently, images taken from different points of view of bridge's structure were used to build the 3D model. The 3D model was completed through the union of several "models" or portions. Each individual model was constituted by three or four pictures taken from different points of view with a convergence angle of approximately $90^{\circ}$, using a digital camera Nikon D200 that had been geometrically calibrated by using the procedure explained in [16]. The whole photogrammetric processing was carried out through the low cost photogrammetric workstation Photomodeler Pro®. First, camera calibration was performed with the same settings during data acquisition and then, all images were oriented in a common coordinate system, thereby producing a 3D model of the whole structure, as shown in figure 4B.

Then, each thermographic image was registered with the 3D model through the marking of at least 6 corresponding points between each thermography and the model. This way, the thermographic texture could be applied to the 3D model, as shown in figure 4A. The thermographic 3D model allows the thermographic interpretation of the bridge as a whole, facilitating, for example, the identification of the arch with more humidity, since it appears as having lower temperature.

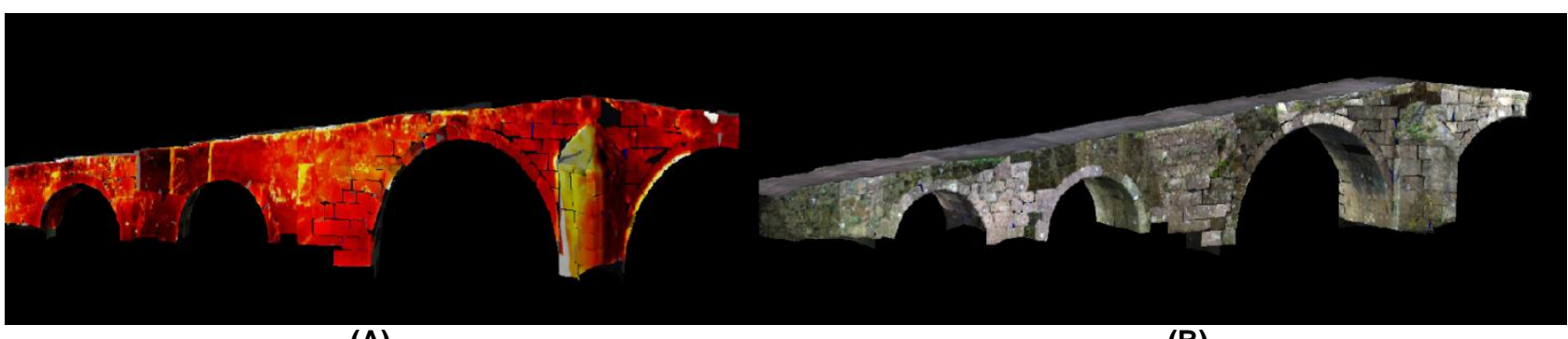

(A)

(B)

Fig.4. Upstream view of the thermographic $3 D$ model $(A)$ generated through the registration of thermographic images in the photogrammetric $3 D$ model of the bridge $(B)$.

Given that the focus of this study was the first arch looking upstream, thermographies of its vault were also registered in the 3D model, enabling the study of the complete vault instead of studying each thermography separately, thus reducing the confusion caused by the lack of reference points in individual thermographies. In order to avoid the effects of the perspective view, each wall, upstream and downstream, is orthogonally projected to its parallel plane.

\subsubsection{Thermographic analysis}

The thermographic study is performed on the thermographic 3D model of the bridge, as mentioned before, due to the possibility of analysing the whole bridge in the same image, or each arch independently. The direct performance of these studies on the thermographies is not possible due to their small field of view. As can be seen in figures 5 and figures 6 , the thermographic resolution is the same in both thermography and orthothermogram, but on the first one only the upper part of the arch can be studied, whereas on the second the whole arch can be analysed.

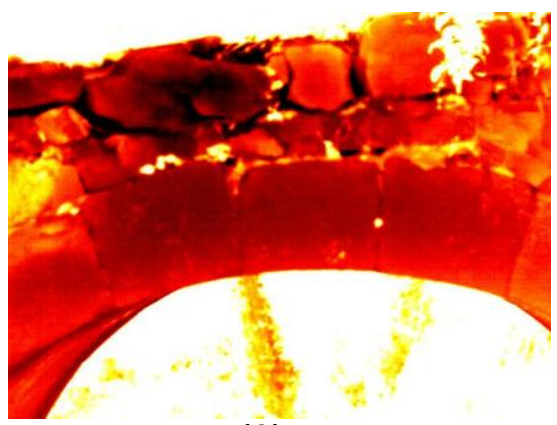

(A)

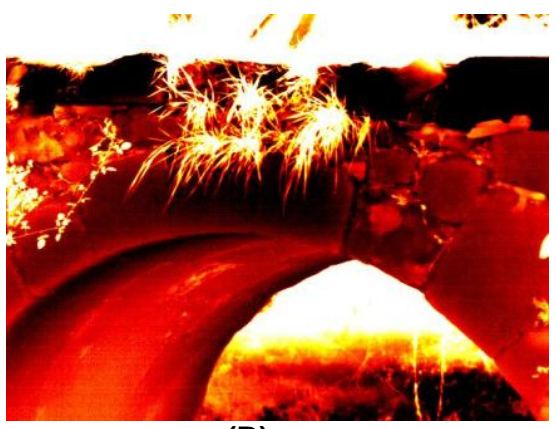

(B)

Fig.5. Thermographies of the first arch looking upstream (A), and downstream (B).

An analysis of the orthothermogram of the upstream wall of the arch (figure 6A) leads to the detection of moisture in the central part of the arch, and near the border with the pathway. This water content becomes more evident in the downstream wall of the same arch (figure 6B), where water can be detected all around the arch in spite of the presence of a large quantity of vegetation hiding part of the faults. From a different point of view, warm temperatures appear in those areas covered by vegetation, which grows mainly in the joints between rocks. 


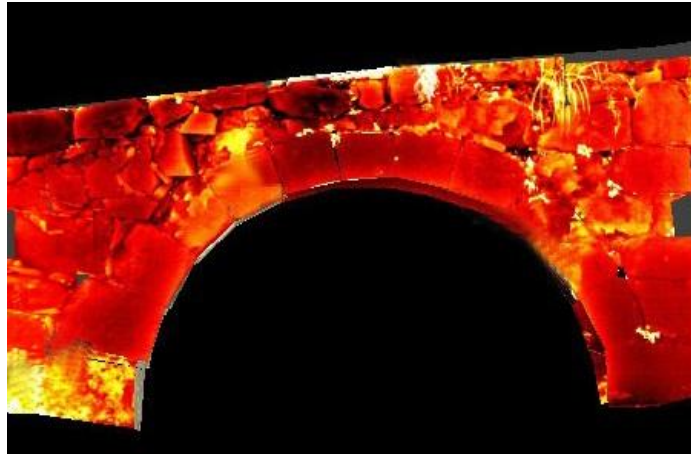

(A)

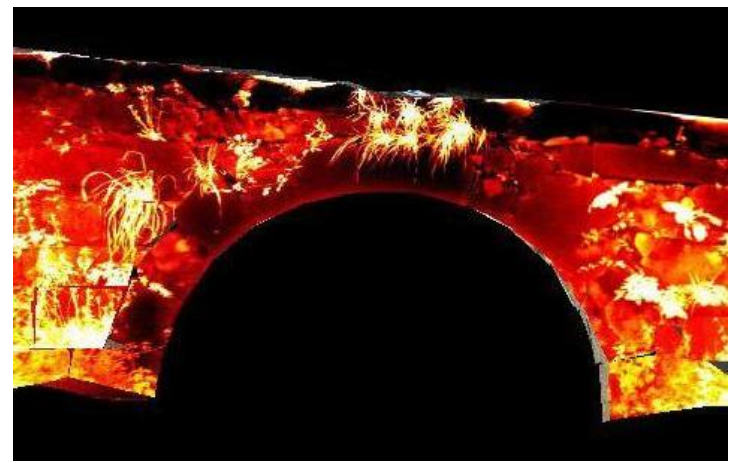

(B)

Fig.6. Orthothermogram of the walls of the arch under study, upstream (A) and downstream (B).

Regarding the vault of the arch under study, the thermographic 3D model shows a more critical presence of water at the edge of the vault, towards the face of the upstream wall. This water content can be seen through the low temperatures appearing as a black red region, marked with a white arrow in figure 7 . The walls of the vault were also orthogonally projected to a plane parallel to their main direction in order to obtain orthothermograms, shown in figure 8, where geometric measurements can be performed together with thermographic studies.

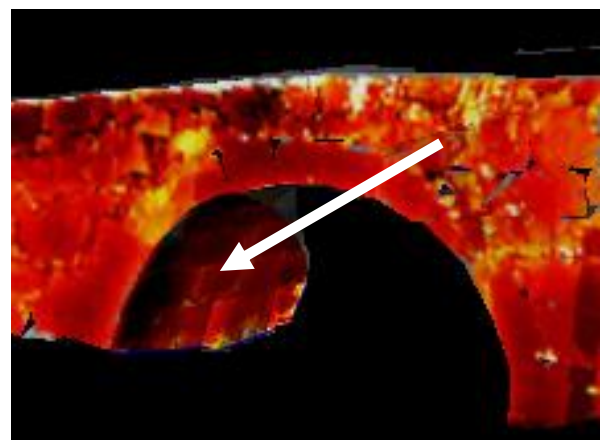

Fig.7. Detail of the thermographic 3D model, focusing on the vault of the arch under study. The white arrow highlights the presence of water detected due to the considerable reduction in the temperature value in comparison with the rest of the vault.

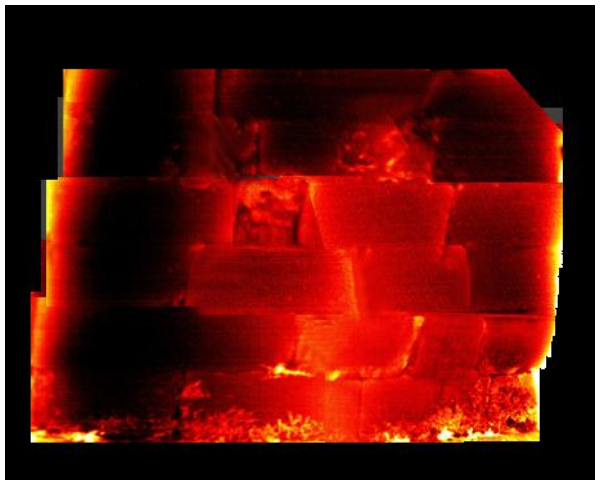

(A)

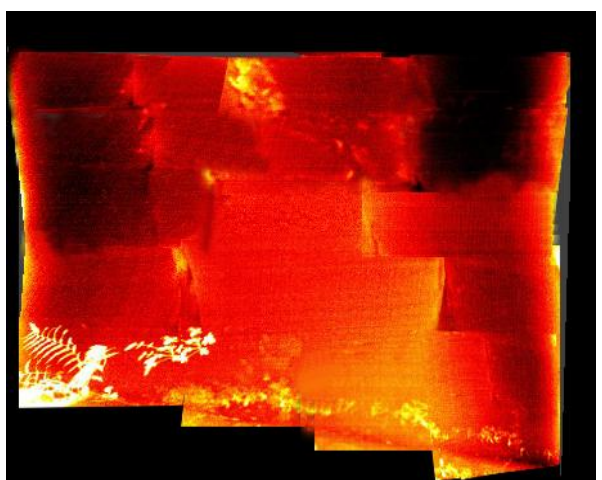

(B)

Fig.8. Orthothermograms of the walls of the vault; looking to the bridge from the upstream side: $(A)$ corresponds to the left wall, and $(B)$ corresponds to the right wall.

\subsection{Ground-penetrating Radar}

The GPR data collected was processed with Reflex W v.5.6 software in order to correct the down-shifting of the radar section due to the air-ground interface and to amplify the received signal, as well as to remove both low and highfrequency noise in the vertical and horizontal directions. The processing sequence applied was: time-zero correction, dewow filtering, gain application, and spatial filtering ("Subtracting average"), and band-pass ("Butterworth") filter. Moreover, due to the barrel geometry of the arch, the data was corrected for topography and the tilt of the antenna considering the precise geometry provided by the 3D model. Static corrections are recommended to improve the accuracy in imaging subsurface features in complex structures, such as this bridge. 
Figure 9A shows the processed data acquired with the $1 \mathrm{GHz}$ antenna along the pathway of the bridge, which shows attenuation of the GPR signal. The reflection produced by the arch-air interface is only clearly identified in the central zones of the bridge (from 1.5 to 2.5 at $14 \mathrm{~ns}$ ). The GPR data recorded over the intrados of the vault arch surface is shown in figure $9 \mathrm{~B}$, where the reflection due to the stone-masonry interface was only clearly identified in the zones contiguous to the keystone of the arch (from 1.0 to $2.0 \mathrm{~m}$ at $20 \mathrm{~ns}$ ). Attenuation of the GPR signal was observed in the regions next to the bridge main walls at both sides of the arch, which most probably indicates that these zones have a higher content of moisture.

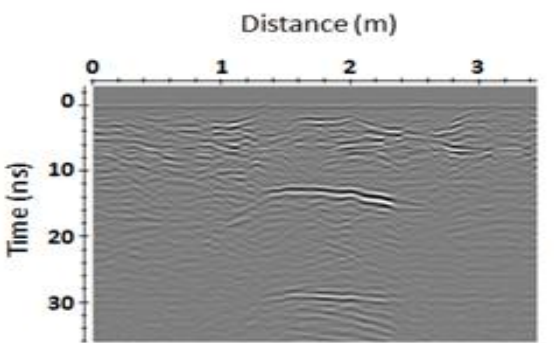

(A)

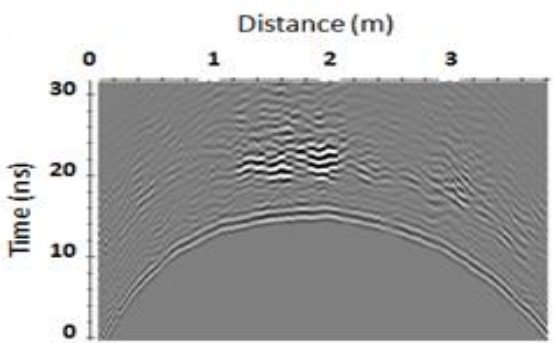

(B)

Fig. 9. Processed $1 \mathrm{GHz}$ data over the pathway of the bridge $(A)$ and over the intrados of the vault arch surface $(B)$.

GPR field data confirmed high moisture content in the internal lateral walls at both sides of the arch in both data acquisition configuration (figure 9). To ratify this interpretation, exhaustive FDTD modelling was used, with the assumed values for the electromagnetic properties shown in table 2. The orthothermograms generated from thermographic 3D model were used to elaborate profiles of the bridge using Matlab ${ }^{\circledR}$ software, and large scale and more realistic models were built. As shown in table 2, three different media were considered based on the results provided by thermography. Yellow areas were assumed to be low moist areas, medium moist for orange areas, and dark red areas were identified as presenting high water content.

Table 2. Electromagnetic properties assumed for media characterization

\begin{tabular}{|l|l|l|}
\hline Medium & Permittivity & Conductivity (S/m) \\
\hline Low moist masonry & 5 & 0.001 \\
\hline Medium moist masonry & 7 & 0.01 \\
\hline Higher moist masonry & 9 & 0.1 \\
\hline Air & 1 & 0.00 \\
\hline
\end{tabular}

Figure 10 shows the synthetic data obtained from the upstream side of the arch, where no attenuation of the signal was observed.

$$
\text { Distance }(\mathrm{m})
$$

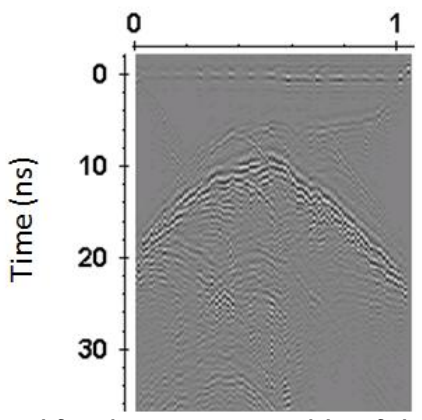

Fig. 10. Synthetic data obtained for the upstream side of the arch. The model was built from the orthothermogram provided in figure $6 \mathrm{~A}$

\section{Results and discussion}

Thermographies were analysed in order to determine whether the cold areas detected were due to water infiltrations in the bridge and not to irregularities in the surface of the stones. This analysis was performed through the study of their location and shape. In the case of the arch with higher water content, this study lead to the detection of anomalies due to damage in the surface of the stones, as shown in figure 11A. In this image a cold area detected in the left wall of the vault is highlighted with a white circle, shown in detail in figure 11B. Although low temperatures are associated in this paper with humidity areas, checking with the visible image (figures 11C and 11D) allowed for the rejection of humidity as the cause for the detected anomaly. 

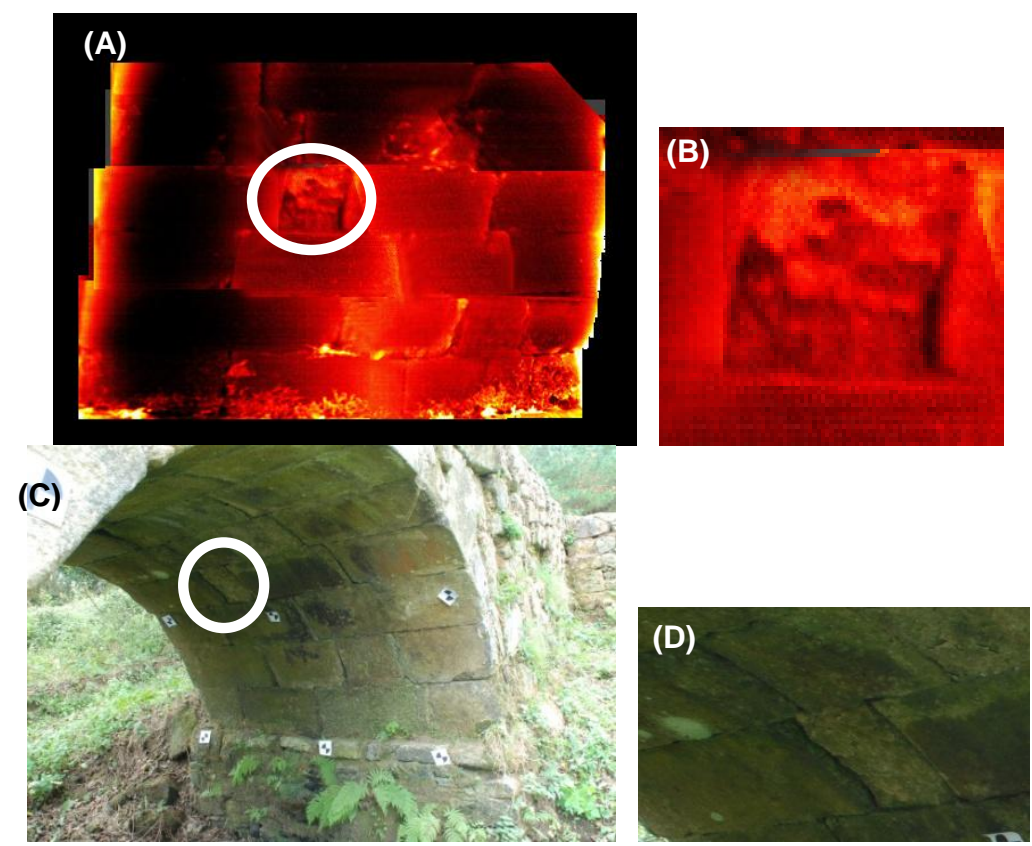

Fig.11. Anomaly detected in the thermography not corresponding to a damp area but to defect in the surface of the stone, $(A)$ and $(B)$ for detail. This confusion was solved by checking the corresponding visible image, $(C)$ and $(D)$ for detail.

Once the whole bridge was analysed, those anomalies classified as moisture were evaluated and compared with the results coming from the field data of the GPR, thus confirming the interpretation of water content around the arch under study performed after the first GPR survey.

However, regarding the GPR results, some difference have been found in results of the field data and the simulation data, since no signal attenuation appears in the synthetic data generated using profiles extracted from the orthothermograms (figure 10), in contrast with the attenuation observed in the field data (figure 9). This difference can be explained by the fact that, in the field data, only the central part of the arch was not attenuated and clearly identified (figure 9A), and the simulation was built from the interpretation provided by thermography, which indicated non critical moist areas in the external stonework of the bridge at the upstream side (figure 6A). The GPR field data was not collected at exactly the same point of thermography, and the difference observed between the synthetic and field data can be produced by the behaviour of the moisture in masonry. Observing the field data, the most relevant attenuation occurs at the lateral walls of the vault, so it seems to indicate that water could be drained from the upper backfill and accumulated in these areas. The orthothermograms produced at the intrados of the vault (figure 8 ) agree with the field GPR data, and ratify this hypothesis.

\section{Conclusions}

Infrared thermography can be effectively used as a non-destructive tool for determining the presence and extent of moisture in masonry walls, provided that areas with water present lower temperature than dry ones due to the cooling effect that evaporation has on the surface. However, attention must be paid during interpretation of thermographic images, as not only humidity areas can be detected: irregular surfaces of the stones also appear at different temperatures due to the different angles of emission and reflection, and vegetation on the surface of the stones appears at higher temperatures given their living nature. The presence of vegetation must also be taken into account when planning the thermographic survey, as it prevents the detection of all the moisture areas in the bridge by hiding evidence of whatever is behind. What is more, the cracks created by the growing roots serve as channels for the water to go into the fill of the bridge. As a result, vegetation not only prevents the detection of anomalies on the surface of the stones, but also helps in the deterioration of the bridge by provoking the appearance of cracks that debilitate the structure.

However, in the case under study vegetation did not prevent infrared thermography and ground-penetrating radar from proving their appropriateness for the identification of moisture areas in masonry bridges. Moisture areas are identified through the comparison of thermographies with ground-penetrating radar results in order to confirm that the signal attenuations in the radargram are due to water in the fill of the bridge, and dismiss other possible causes, such as other conductive and molecular relaxation losses, or scattering losses. On the other hand, thermographic results can also be used for the generation of a synthetic model of the bridge towards the FDTD simulation of the behaviour of the bridge, which allows the extraction of subtle interpretational information from real data to assist its interpretation. 


\section{ACKNOWLEDGMENTS}

The authors would like to give thanks to Consellería de Economía e Industria (Xunta de Galicia), Ministerio de Economía y Competitividad and CDTI (Gobierno de España) for the financial support given through human resources grants (FPU AP2009-1144, IPP055-EXP44) and projects (INCITE 10MDS031E and IDI-20101770). All programmes are cofinanced by the Fondo Europeo para el Desarrollo Regional (FEDER).

\section{REFERENCES}

[1] Schuller M.P., "Nondestructive testing and damage assessment of masonry structures", Prog. Strct. Engng. Mater. vol. 5, pp. 239-251, 2003.

[2] Well G.J., Graf R.J., Forister L.M., "Investigations of Hazardous Waste Sites Using Thermal IR and Ground Penetrating Radar". Photogrammetric Engineering \& Remote Sensing, vol. 60, pp. 999-1005, 1994.

[3] Válek, J., Kruschwitz, S., Wöstmann, J., Kind, T., Valach, J., Köpp, C., Lesák, J., "Nondestructive investigation of wet building material: multimethodical approach", Journal of Performance of Constructed Facilities, vol. 24, pp. 462-472, 2010.

[4] Rosina E., Spodek J., "Using infrared thermography to detect moisture in historic masonry: A Case Study in Indiana", APT Bulletin, vol. 34, pp. 11-16, 2003.

[5] Clark M., Forde M.C., "Infrared thermography assessment of masonry arch bridges: laboratory and field case studies", International Symposium NDT-CE, Berlin, Germany, September 16-19, 2003.

[6] Trela, C., Wstman, J., Kruschwitz, S., "Contribution of radar measurements to the inspection and condition assessment of railway-bridges - Case study at a historic masonry arch bridge in Olenica / Poland", WIT Trans. Built Env., vol. 97, pp. 535-544, 2008.

[7] Hing C.L.C., Halabe-Udaya B., "Nondestructive testing of GFRP bridge decks using ground penetrating radar and infrared thermography", Journal of Bridge Engineering, vol. 15(4), pp. 391.398, 2010.

[8] Carlomagno, G.M., Di Maio, R., Fedi, M., Meola, C., "Integration of infrared thermography and high-frequency electromagnetic methods in archaeological surveys", Journal of Geophysics and Engineering, vol. 8 (3), S09, 2011.

[9] Solla, M., Lorenzo, H., Rial, F.I., Novo, A., "Ground-penetrating radar for the structural evaluation of masonry bridges: Results and interpretational tools", Const. Build. Mat., vol. 29, pp. 458-465, 2012.

[10] Lubowiecka, I., Arias, P., Riveiro, B., Solla, M., "Multidisciplinary approach to the assessment of historic structures based on the case of a masonry bridge in Galicia (Spain)", Computers and Structures, vol. 89, pp. 1615-1627, 2011.

[11] Luhmann, T., Robson, S., Stephen, K., Harley, I., "Close Range Photogrammetry: Principles, Methods and Applications", Whittles publishing of Caithness: Caithness, Scotland, UK, 2006.

[12] Millard, S.G., Shaw, M.R., Giannopoulos, A., Soutsos, M.N., "Modelling of subsurface pulse radar for nondestructive testing of structures", ASCE Jour. Mater. Test. Civil Eng., vol. 10, pp. 188-196, 1998.

[13] Jol, H.M., "Ground penetrating radar: theory and applications", Elsevier Science, 2009.

[14] ISO 18434-1:2008 (E). Condition monitoring and diagnostics of machines - thermography - part 1: general procedures.

[15] Daniels, D.J., "Ground penetrating radar", London: The institution of electrical engineers, 2004.

[16] Riveiro, B., Caamaño, J.C., Arias, P., Sanz, E., "Photogrammetric 3D modelling, FEM and mechanical analysis of masonry arches behaviour: an approach based on discontinuous model of voussoirs", Automation in Construction, vol. 20, pp. 380-388, 2011. 